\title{
RNA-SEQ ANALYSIS IN GILLS OF ATLANTIC SALMON (SALMO SALAR) INFECTED WITH NEWLY IDENTIFIED ISAV STRAINS IN THE ATLANTIC CANADA REGION
}

\author{
Francis LeBlanc $^{1}$, Steven Leadbeater ${ }^{2}$, Mark Laflamme ${ }^{1}$, Nellie Gagné ${ }^{1^{*}}$ \\ ${ }^{1}$ Fisheries \& Oceans Canada, Gulf Fisheries Center, Moncton, NB, Canada; \\ ${ }^{2}$ Fisheries \& Oceans Canada, St Andrews Biological Station, St Andrews, NB, Canada;
}

The Infectious salmon anemia virus (ISAV) is an important viral disease of farmed Atlantic salmon (Salmo salar) which has caused severe financial losses for salmon farmers around the world, including Atlantic Canada. It is listed as an OIE notifiable disease and to this day eradication of infected cages remains the current practice in many countries to mitigate the spread of the virus. All strains known to display any level of virulence are characterised by deletions in the highly polymorphic region (HPR) of the hemagglutinin-esterase (HE) protein compared to ISAV-HPR0 strains and are designated ISAVHPR $\Delta$. In contrast, HPR0 strains are non-virulent and not detected by viral culture. In Atlantic Canada, improved management and husbandry practices resulted in no outbreaks caused by ISAV-HPR $\Delta$ strains from 2007 to 2012, with however ISAV-HPR0 strains (European genotype) still being detected. Starting in 2012, new ISAV-HPR $\Delta$ strains were responsible for disease outbreaks in fish farms in Nova Scotia, Newfoundland and New-Brunswick. This study was thus designed to characterize virulence associated to three of the newly identified ISAV-HPR $\Delta$ strains and investigate gene expression responses in gills of infected fish using RNA-Seq. All three ISAV-HPR $\Delta$ strains studied through the use of in vivo challenges resulted in cumulative mortalities below 40 percent and caused the differential expression of up to 1000 genes at the peak of infection compared to non-infected fish. Many genes linked to innate immunity were over-expressed; similar to what had been observed in the head-kidney through previous work. The use of RNA-Seq also enabled us to look at ISAV transcript abundance and showed that segment 8 had the highest abundance of all 8 segments of the genome. This information has given us great insight on how ISAV interacts with his host during the course of an infection.

*Corresponding author. Phone: (506) 851-7478. Fax: (506) 851-7732.

E-mail: Nellie.Gagne@dfo-mpo.gc.ca

Keywords: Atlantic salmon, ISAV, RNA-Seq, Transcriptome, ISAV transcript abundance 